\title{
The effect of international trade on mark-ups distribution
}

Lourdes Moreno and Diego Rodríguez

Universidad Complutense de Madrid and GRIPICO

\begin{abstract}
:
This paper presents empirical evidence about the relationship between market openness and markup distribution of manufacturing firms. The empirical analysis uses a panel data set of Spanish firms in the period 1990-2005, with a structural approach to identify individual mark-ups. The results point out that tougher competition associated to openness reduces marginal costs and prices, while it increases the average firm size. However, the evidence about the effect on average markups and the dispersion of performance variables across industries is weaker. These results partially support the theoretical predictions by the recent literature on efficiency heterogeneity and international trade and, in particular, Melitz and Ottaviano (2008).
\end{abstract}

JEL Classification Numbers: F12, L60, L13

Corresponding author:

Diego Rodriguez Rodríguez

Departamento de Economia Aplicada II

Universidad Complutense de Madrid

Campus de Somosaguas 28223, Madrid, Spain

Tel: 34-91-3942477

E-mail:drodri@ccee.ucm.es

Acknowledgements: Authors acknowledge financial support from the Spanish Ministry of Education (reference ECO2010-18947). 


\section{Introduction}

The influential paper by Melitz (2003) stimulated a huge literature that explains the decision to export with the incorporation of intraindustry heterogeneity in productivity and size. According to this approach, the exposure to trade implies two selection processes: only the most productive firms enter into the export market and the less productive firms exit the domestic market. A main characteristic of such an approach is that it models the demand side using CES preferences which, as usual, generate constant markups.

Later, Melitz and Ottaviano (2008) (MO hereinafter) proposed an alternative framework that establishes predictions on the distribution (average and variance) of four performancemeasures: productivity, size, price and markup. This model is based on a monopolistically competitive framework with heterogeneous firms and endogenous differences in the 'toughness' of competition across countries, reflected by the number and average productivity of competingfirms in that market. Though this model follows many features of Melitz (2003), it has two specific characteristics that determine different and more realistic predictions about markup distribution. Firstly, demand side is specified using a linear demand system with horizontal product differentiation developed by Ottaviano et al (2002). It allows authors to incorporate endogenous markups. ${ }^{1}$ Secondly, trade operates through an increase of product market competition, instead of through the increased labour market competition channel. Firms respond to this tougher product market competition by setting a lower markup that could outweigh the selection effect according to which the most productive firms survive and set higher markups.

This paper tests some theoretical predictions of MO with a panel data set of Spanish manufacturing firms in the period 1990-2005. Particular attention is devoted to mark-ups distribution, which has been less analyzed that productivity heterogeneity. Partially, it could be due to the CES assumption in Melitz (2003) approach. Additionally, mark-up is a more difficult variable to approach empirically than productivity. In this context, some few alternatives have been used to estimate margins. For example, Roeger (1995) suggested a methodology that has been extensively used in the empirical literature on markups, though it incorporates the key assumption of constant returns to scale. An alternative way to estimate mark-ups was proposed by De Loecker and Warzynski (2012). That approach has been used recently by Bellone et al (2012) in a paper closely related to this one. Chen et al (2009) have also departed from the MO to test inter-country differences in the sectoral openness to trade. However, their objective is slightly different to the goal in this paper, insofar as they do not estimate competition effects at the country level, but differences across the same industries located in

\footnotetext{
${ }^{1}$ Alternatively, Feenstra and Weinstein (2010) use translog preferences to estimate the impact of globalization on markups and welfare.
} 
different countries. They approach margins with a variable that measure turnover over variable costs, and use an error correction model where the endogeneity problem for openness at the industry level is taken into account.

In this letter, however, we estimate price-cost margins using the methodology proposed by Bernstein and Mohnen (1991). We have implemented that methodology in Moreno and Rodríguez (2010) to compare the differences in average margins according to the degree of persistence in export activity. Although it requires more information than other approaches, and a more complex econometric methodology than Roeger (1995), an interesting feature of this approach is that it allows us to estimate not only the firms' margins but also marginal costs that we need to test other predictions of MO. We proceed in two stages. Firstly, we estimate a structural model that allows us to estimate margins and marginal cost for each firm and each year. We then calculate within-industries averages and variance for these two performance variables and other: size, prices and total productivity factor. In a second step, we relate those statistics with inter-industry differences in market openness approached by export and import intensities.

The structure of the paper is as follows. Section 2 summarizes main features of MO and briefly discusses how to approach empirically performance measures. Section 3 discusses the data and empirical results, and Section 4 concludes.

\section{Markup heterogeneity and international trade}

\subsection{The MO predictions}

The MO model incorporates endogenous markups using the linear demand system with horizontal product differentiation developed by Ottaviano et al (2002). In that approach, price elasticity does not only depend on product differentiationas in the CES demand model, but also on the average prices and the number of competing varieties. With respect to firms, they face initial uncertainty concerning their future productivity when making a costly and irreversible investment decision prior to entry. As usual, such uncertain outcome for marginal cost (the inverse of productivity) is modelled as a draw from a common and known distribution $\mathrm{G}(\mathrm{c})$ with support on $\left[0, c_{M}\right]$. The key parameter is the level of marginal cost $c_{D}$ in which the firm is indifferent about remaining in the industry or exiting. Specifically, all firms with $c>c_{D}$ exit, while all firms with cost $c<c_{D}$ earn positive profits and remain in the industry. Firms with lower marginal costs set lower prices and obtain higher profits than high-cost firms. However, they also set higher mark-ups because they do not fully translate cost advantages to prices. This is a selection effect. 
Average productivity will be higher when sunk costs are lower andproduct varieties are closer substitutes. Larger markets induce tougher selection (lower cutoff $c_{D}$ ) with more product variety and lower average prices. In this setting, firms are bigger and earn higher profits. However, average mark-ups are lower as the competition effect outweighs the selection effect.Additionally, the chosen parameterizationfor the distribution of marginal costs allowsauthors to obtain some predictions about the dispersion ofthe performance variable. Specifically, a bigger market reduces the variance of average prices, costs and markups. This is the result of the selection effectthat reduces the support of these distributions for any distributionG(c). With respect to firm size, its variance is bigger in larger markets due to the direct magnifying effect of market size. In sum, the predictions can be summarized as follows: the average (and variance) of price, cost and mark-ups is a decreasing function of market size. The opposite is expected with respect to firm size.

This set of predictions is valid for both a closed economy and an open economy without trade costs. As MO point out, free trade is equivalent to an increase in market size.With non-integrated markets, two dimensions are introduced to differentiate countries: market size and barriers to imports (in the classical way of delivered costs). With trade frictions, the cutoff is always lower than in an economy with free trade. This reduction in the cutoff, which is dependent on trade costs, forces to least productive to exit. The underlying reason is that more import competition increases the price elasticity of the residual demand of all firms. Though surviving firms are more productive and have higher markups, the average markup is reduced. In sum, the pro-competitive effect outweighs the selection effect.This result is similar to that found in Melitz (2003) but it works in a different way.While in the latter trade induces increased competition as consequence of more competition in the labour market, in MO model product market competition is the only channel: labour market does not play any role due to the elastic labour supply.

This paper focuses mainly on the differences on trade openness, as a proxy for trade barriers, on the distribution of performance measures. Additionally, MO also analyzes the second dimension to explain differences across countries: market size. Again, the effect goes through the cutoff $c_{D}$ : when trade costs are symmetric, the larger country will have a lower cutoff, and thus higher average productivity, along with lower mark-ups and prices (relative to the smaller country).However, this market size effect refers to "home" market, while "partner" size has not any effect in the long-run. MO argument that, from the export side, this is due to larger market opportunities are offset by competitiveness effect. In a similar way, from the import side, the increased level of domestic competition due to a larger trade partner, would be exactly offset by a smaller proportion of entrants 
in the long-run. Of course, as they recognize the exact outcome of these trade-offs are derived from the specific functional forms used in the analysis.

Finally, we should take into account that the predictions of the MO model are made in terms of average and variance of firm performance measures. We implement empirically such a framework by using industry average (and variance) performance measures, though those measures are estimated at the firm-level.

\subsection{Empirical approach to estimate the mark-ups and the marginal cost}

Among the performance variables considered in the MO model, markup and marginal cost are the most difficult to approach empirically. With that aim, we use the methodology proposed by Bernstein and Mohnen (1991). ${ }^{2}$ It is based on a structural specification which comprises a translog cost function, a price-cost margin equation and a factor share equation. The cost function is defined as follows:

$$
C=C\left(P_{f}, Y, t\right)
$$

where $P_{f}$ is a vector of prices of factors (labor $\left(X_{L}\right)$, intermediate inputs $\left(X_{M}\right)$ and capital stock $(K)$ ) and $t$ is a time trend which represents the state of technology. Factor prices are assumed to be exogenous to firms. For the empirical specification we use a translog cost function such as:

$$
\begin{aligned}
\ln C^{*} & =\ln \left(\frac{C}{P_{K}}\right)=\beta_{0}+\beta_{1} \ln Y+\beta_{2} \ln \frac{P_{L}}{P_{K}}+\beta_{3} \ln \frac{P_{M}}{P_{K}}+\frac{1}{2} \beta_{4}(\ln Y)^{2}+\beta_{5} \ln Y \ln \frac{P_{L}}{P_{K}} \\
& +\beta_{6} \ln Y \ln \frac{P_{M}}{P_{K}}+\beta_{7} \ln \frac{P_{L}}{P_{K}} \ln \frac{P_{M}}{P_{K}}+\frac{1}{2} \beta_{8}\left(\ln \frac{P_{L}}{P_{K}}\right)^{2}+\frac{1}{2} \beta_{9}\left(\ln \frac{P_{M}}{P_{K}}\right)^{2}+\beta_{10} t+\varepsilon
\end{aligned}
$$

In the previous specification, the restrictions corresponding to a degree one homogeneous cost function in variable input prices, $P_{L}$ (labour), $P_{M}$ (materials) and $P_{K}$ (capital stock) have been imposed. Additionally, $t$ is a time trend which represents the state of technology.With respect to the margin equation, we consider that firms sell a differentiated product in markets characterized by imperfect product competition.In this sense, the price-cost margin can be expressed, as usual, from:

$$
P(1-\mu)=C^{\prime}
$$

\footnotetext{
${ }^{2}$ Moreno and Rodriguez (2010) use this methodology to analyze differences in average margins according to export status. In this paper, instead of assuming a short-term context with a variable cost function, a long- term context is considered.
} 
Where $C^{\prime}$ is marginal cost, $P$ is product price and $\mu$ is the corresponding price-cost margin. The price-cost margin can be rewritten as follows:

$$
\frac{P Y}{C}\left(1-\mu_{s}+\gamma D\right)=\beta_{1}+\beta_{4} \ln Y+\beta_{5} \ln \frac{P_{L}}{P_{K}}+\beta_{6} \ln \frac{P_{M}}{P_{K}}+\xi
$$

where ( $P Y / C$ ) the ratio of nominal sales (revenues) to cost. In (3) the margin of the firm has been parameterized to take into account the heterogeneity of firms across different industries $\left(\mu_{s}\right)$ and the impact of the business cycle (D). Cost sharesarealso included in the set of equations for the sake of efficiency as:

$$
\begin{aligned}
& \frac{P_{L} X_{L}}{C}=\beta_{2}+\beta_{5} \ln Y+\beta_{7} \ln \frac{P_{L}}{P_{M}}+\beta_{8} \ln \frac{P_{L}}{P_{K}}+\tau \\
& \frac{P_{M} X_{M}}{C}=\beta_{3}+\beta_{6} \ln Y+\beta_{7} \ln \frac{P_{L}}{P_{M}}+\beta_{9} \ln \frac{P_{L}}{P_{K}}+v
\end{aligned}
$$

The equation system to be estimated is comprised of (1), (3), (4) and (5), where (3) is a non-linear function. The estimated parameters allow us to obtain individual marginal cost and margins.

\section{Data and empirical results}

The sample used consists of an unbalanced panel of Spanish manufacturing firms for the period 1990-2005. The variables were obtained from the Survey on Business Strategies (ESEE) that excludes manufacturing firms with less than 10 employees, while larger firms are randomly sampled by industry (at two-digit NACE level) and size segment. All information, including price variations for outputs and inputs is obtained at the firm level (see Appendix for the construction of variables). The total number of observations, after those with incomplete information were dropped was 22,027. Descriptive statistics for all variables and sub-samples (non-exportersand exporters, non-importers and importers) are showed in Table A.1 of the Appendix.

In the first stage, we estimate the structural model explained in the previous section that allows us to estimate the margins and the marginal cost of the firms. Table 1 shows the joint estimate of the translog cost function, the labor and material cost shares and the margin equation by the Generalised Method of Moments (GMM). Input prices are considered exogenous, while endogeneity in sales is assumed. The estimation is carried out by instrumenting the endogenous variables with their crosssection lagged values at $\mathrm{t}-2$. The Sargan is presented at the bottom of the column and the validity of instruments is accepted. 
[Table 1]

With respect to margins, the first column in Table 1 shows the parameter $\mu_{s}$, calculated as the average of a set of 14 industrial dummies. The F-test at the bottom of Table 1 confirms their significance. The parameter for firm indicator of demand evolution $(D)$ presents the expected positive sign, which suggests a procyclical behaviour of margins. This parameter, multiplied by the average value of demand evolution, and added to estimated parameter $\mu_{\mathrm{s}}$, allows us to obtain an average margin of $16.5 \%$ for all firms in the complete period.

The estimated parameters allow us to obtain predicted marginal costs and mark-ups for each firm. With respect to the others variables referred in the MO paper, the prices, has been calculated departing from firm-level price variation provided by firms. Firm size has been approached with deflated sales, by using firm-level price variations. Although the MO predictions are in terms of productivity levels, we also consider the growth of total factor productivity (TPF) -approached by Solow residual, due to the marginal cost can be consider the inverse of the productivity levels in the MO model.

In the second stage we are going to relate these four performance variables (marginal costs, prices, markups and size) with the degree of openness. As was previously pointed out, larger openness and market-size have similar results: in both cases the cutoff that determines the number of surviving firms is lower. Therefore, more openness may be associated to lower average (and variance) price, cost and markups, while larger average (and variance) size is expected.

Four measures are used to approach empirically the degree of openness: the percentage of exporters (importers) with respect to all firms (PEX and PIM, respectively) and export (import) propensity (EP and IP, respectively), defined as the percentage of exports (imports) over total sales. Those industries with a larger percentage of exporters are (as expected) also those with a larger export propensity. The same result is obtained when import instead of export is considered. We test the predictions of the MO with inter-industry correlations, where industries are defined at two-digits NACE. Averages and variances for each performance variable and openness measure are calculated as intra-industry averages and dispersion (variance).

[Table 2] 
Table 2 shows the correlations between the four measures of openness and performance variables. As can be seen, the obtained signs are as expected. Higher openness, both in terms of the percentage of exporters and importers and with respect to export and import propensity, shows a negative correlation with average marginal costs and prices. The latter result is in accordance with Chen et al. (2009), who find a competitive effect of trade openness, approached by import competition, on prices in the short run. However, we find weaker evidence that they are less dispersed. Additionally, as expected, more openness is positively correlated with average firm size, while the distribution is more disperse.

With respect to markups, though we find the expected negative sign in average and variance, the correlation is not statistically significant. This result can be interpreted as the two expected effects of openness on markups, pro-competition and selection effect, are almost mutually cancelled. In our previous paper (Moreno and Rodríguez, 2010), the results were also not conclusive: non-exporters have smaller margins than persistent exporters (selection effect) but larger export ratio is negatively associated with margins for persistent exporters (pro-competition effect). In a similar way, Chen et al. (2009), find a negative effect of the trade openness on the mark-ups in the short run but the long run effects are most ambiguous and may even be anti-competitive. Bellone et al. (2012) also obtain a negative relationship between markups and the intensity of import competition. However, that relationship is positive with export participation, though it seems to be lower for firm facing more efficient competitors abroad and with higher transport costs.

Finally, with respect to the growth of TFP, and as can be seen in the last row in Table 2 the correlation supports previous results with respect to marginal costs: tougher selection effect in larger markets produce stronger productivity growth. This is a similar result to Chen et al. (2009), who also obtain a positive effect of the import ratio on labour productivity in the short run.

\section{Conclusions.}

There is abundant evidence about how trade flows can explain productivity heterogeneity among firms. This paper contrasts the set of theoretical predictions developed by Melitz and Ottaviano (2008) which obtains predictions about changes in mark-ups, marginal cost, prices and other performance measures induced by trade openness. The results obtained for a long unbalanced panel of Spanish manufacturing firms support the hypothesis that tougher competition linked to openness reduces the average of marginal costs and prices, while it increases the average firm size. However, the evidence about the effect on average markups is weaker. 
With respect to the relationship between the variance of the performance variables and the trade openness degree the results are no conclusive. Though we obtained the signs predicted by MO, the inter-industry correlation is quite low and non-significant. Additional empirical evidence with different approaches seems necessary. 


\section{Appendix: Variable definitions and descriptive statistics}

$C$ (Costs):The sum of intermediate consumption (raw materials purchases, energy and fuel costs and other external services) plus labor costs minus the stock variation plus.

$D_{i t,}$ (Individual indicator of the business cycle in all markets): In the ESEE survey, each firm identifies the behavior of market demand during one year with respect to the previous year according to three different categories: recession (1), stability (2) and expansion (3).

$P$ (Price index for output sold): The surveyed firms give annual information about markets served (up to five), identifying their relative importance (in percentage) in total sales of the firm. This information allows us to calculate a price index for all markets and for each market, using the proportions with respect to total sales as weighting.

$K$ (Capital stock): It is net stock of capital for equipment in real terms. It is calculated by using the perpetual inventory formula.

TFP growth (Solow residual): It has been calculated using the Tornqvist index, $T F P=y-s_{L} l-s_{K} k-s_{M} m$, where $y$ is the real output variation and the weights $s$ are the annual cost shares of each input.

Table A.1 Variable descriptive firms (logarithmic variations rates, 1991-2005)

\begin{tabular}{l|c|c|c|c|c}
\hline \hline & All firms & $\begin{array}{c}\text { Non- } \\
\text { exporters }\end{array}$ & Exporters & $\begin{array}{c}\text { Non- } \\
\text { importers }\end{array}$ & Importers \\
\hline Output (volume terms) & 3.1 & 1.4 & 4.1 & 1.3 & 4.2 \\
Output (nominal terms) & 4.6 & 3.0 & 5.5 & 2.9 & 5.5 \\
Cost per worker ( $\mathrm{P}_{\mathrm{L}}$ ) & 4.8 & 4.8 & 4.8 & 4,8 & 4,9 \\
Price index for intermediate & 3.3 & 3.7 & 3.1 & 3.6 & 3.1 \\
inputs & & & & & \\
Price of capital & -1.5 & -1.6 & -1.5 & $-1,6$ & $-1,5$ \\
Stock of real capital & 6.2 & 5.9 & 6.4 & 5.4 & 6.6 \\
Cost & 5.2 & 4.2 & 5.8 & 3.9 & 6.0 \\
Number of observations & 19244 & 7153 & 12091 & 7032 & 12.212 \\
\hline \hline
\end{tabular}




\section{References}

Bernstein, J. and P. Mohnen (1991): "Price-Cost Margins, Exports and Productivity growth: with an Application to Canadian Industries", Canadian Journal of Economics, 24, 638-659.

Bellone, F., Musso, P., Nesta, L. and F. Warzynski (2012): "Productivity, Trade and Endogenous Mark-ups: Testing some Micro-level Implications of the Melitz-Ottaviano Model”, mimeo.

Chen, N., J. Imbs and A. Scott (2009): "The dynamics of trade and competition", Journal of International Economics, 77, 1, 50-62.

De Loecker, J. and Warzynski, F., (2012): “Markups and Firm-Level ExportStatus”, American Economic Review, 102(6), pp. 2437-2471.Feenstra, R. and D. Weinstein (2010): “Globalization, Markups and the U.S. Price Level”, Working Paper 15479, NBER.

Melitz, M.J. (2003): "The impact of trade on intra-industry reallocations and aggregate industry productivity”, Econometrica, 71, 6, 1695-1725.

Melitz, M. J. and G.I.P. Ottaviano (2008): "Market Size, Trade, and Productivity", The Review of Economic Studies, 75, 295-316.

Moreno, L. and D. Rodríguez (2010): “Export activity, persistence and mark-ups”, Applied Economics,42, 475-488.

Ottaviano, G.I.P., T. Tabuchi and J.F.Thisse (2002): “Agglomeration and Trade Revisited”, International Economic Review, 43, 409-436.

Roeger, W. (1995): “Can imperfect competition explain the difference between primal and dual productivity measures? Estimates for U.S. Manufacturing”, Journal of Political Economy, 103 (2), 316-330. 
Table 1

Cost Function, Cost Shares and Margin Equation

(Joint estimate by GMM)

\begin{tabular}{ccc}
\hline \hline & Coefficients & t-statistics \\
\hline$\beta_{0}$ & -1.276 & -0.2 \\
$\beta_{1}$ & 0.909 & 16.9 \\
$\beta_{2}$ & -0.102 & -0.1 \\
$\beta_{3}$ & 3.474 & 2.0 \\
$\beta_{4}$ & 0.001 & 0.1 \\
$\beta_{5}$ & -0.005 & -1.2 \\
$\beta_{6}$ & 0.012 & 2.9 \\
$\beta_{7}$ & -0.221 & -1.4 \\
$\beta_{8}$ & 0.038 & 0.5 \\
$\beta_{9}$ & -0.094 & -0.8 \\
$\beta_{10}$ & -0.029 & -2.9 \\
Mov1 & 5.912 & 2.2 \\
Mov2 & -7.604 & -2.4 \\
$\mu_{\mathbf{s}}$ & $\mathbf{0 . 1 2 1}$ & $\mathbf{2 . 9}$ \\
$\mathbf{D}$ & $\mathbf{0 . 0 2 1}$ & $\mathbf{1 1 . 8}$ \\
\hline & & \\
AverageMargin & $\mathbf{0 . 1 6 5}$ & $\mathbf{4 . 2}$ \\
\hline
\end{tabular}

Sargan test

$13.7(16)$

Industrial dummies F-test (cost)

$27.5(19,17582)$

Industrial dummies F-test

$147.5(13,17588)$

(margin)

Observations

17601

Years

1992-2005

- t-statistics are robust to heterocedasticity.

- In the Sargan test and industrial dummies F-test, the degrees of freedom are in parenthesis. 
Table 2

Correlation between performance measures and the openness degree (export)

\begin{tabular}{lcccc}
\hline \hline & \multicolumn{2}{c}{ PEX } & \multicolumn{2}{c}{ EP } \\
\cline { 2 - 5 } & Average & Variance & Average & Variance \\
Marginal cost & $-0.419(0.07)$ & $-0.176(0.47)$ & $-0.455(0.05)$ & $-0.252(0.29)$ \\
Price & $-0.437(0.06)$ & $-0.029(0.90)$ & $-0.484(0.04)$ & $-0.147(0.55)$ \\
Markup & $-0.044(0.86)$ & $-0.297(0.22)$ & $-0.087(0.72)$ & $-0.162(0.50)$ \\
Size & $0.437(0.06)$ & $0.411(0.08)$ & $0.477(0.04)$ & $0.407(0.08)$ \\
Productivity (TFP) & $0.624(0.00)$ & $-0.155(0.53)$ & $0.490(0.03)$ & $-0.062(0.80)$ \\
& \multicolumn{3}{c}{ PIM } & \\
& \multicolumn{3}{c}{ IP } \\
Marginal cost & $-0.513(0.02)$ & $-0.106(0.67)$ & $-0.613(0.01)$ & $-0.102(0.68)$ \\
Price & $-0.505(0.03)$ & $0.014(0.95)$ & $-0.647(0.00)$ & $0.049(0.84)$ \\
Markup & $0.020(0.93)$ & $-0.245(0.31)$ & $-0.125(0.61)$ & $-0.184(0.45)$ \\
Size & $0.506(0.03)$ & $0.313(0.13)$ & $0.535(0.02)$ & $0.359(0.13)$ \\
Productivity (TFP) & $0.719(0.00)$ & $0.037(0.88)$ & $0.716(0.00)$ & $0.004(0.98)$ \\
\hline \hline
\end{tabular}

Note: Standard deviations in parenthesis. 